\title{
Knowledge management, project integration and corporate sustainability: is there a link?
}

Everton Michels, Paulo Eduardo Antunes Grijó, Elizandra Machado and Paulo Mauricio Selig, Brazil

\begin{abstract}
The objective of this study was to analyse the possible use of knowledge management as a means to assist in project integration and corporate sustainability. Therefore, a qualitative, exploratory and descriptive research study was developed, through which some useful properties were found that could minimise this gap. From this, one can see that the link between knowledge management and project management is of utmost importance to the natural integration of the portfolio, and contributes effectively and adequately to corporate sustainability.
\end{abstract}

Keywords: knowledge management; project integration; corporate sustainability.

\section{Introduction}

Currently, the world is taking broad steps with respect to project management (PM). In order to better integrate all parties involved and provide corporate sustainability, another area appears to be suitable for supporting this endeavour; namely, knowledge management (KM). A considerable gap is currently perceived between these two important areas which actually complement each other. However, KM provides some practices, methods and techniques to address these concerns, to ease portfolio integration and make corporate sustainability more effective in a way that adequately satisfies all integration, information exchange and knowledge (Drucker 1998, 2003; Peppard 2007).

A large problem in regards to portfolio management is the integration of projects and programs, which end up complicating the creation of a more effective and continuous sustainability, and not allowing for a better balance among the corporation's social, economic and environmental responsibilities. Some researchers link knowledge and learning to better performance in integrating projects (Reich, et al. 2008). Thus, using this information as a starting point, the objective of this study was to analyse the possibility of using of KM as a means to assist in project integration and corporate sustainability.

\section{Research method}

When defining the method for a comprehensive review of the literature, two main criteria have to be identified and clarified: (1) the sources (Webster \& Watson 2002), and (2) the search strategy (Cooper 1998; Levy \& Ellis 2006). Often, a researcher when searching for a key topic area will identify a search term (Cooper 1998; Leedy \& Ormrod 2001) and search for this in the title, abstract and keywords - to locate papers that are specifically focused on the target topic.

This study was developed from a systematic literature review and divided into four steps:

Step 1: began with an exploratory search in databases such as Scopus and Web of Knowledge to identify gaps in the implementation of KM in PM in order to improve sustainability, with the intention of identifying keywords, outstanding authors and relevant journals for the study. 
Step 2: a search string (set of keywords and logical operators to be used in searches in the selected databases) was developed based on the results of Step 1, which revealed a higher concentration in the terms "knowledge management", "project management" and "sustainability".

Step 3: the results of Step 2 were passed through three filters. The first filter sought to limit the number of papers found in order to focus on the areas that are part of the PMSURVEY.ORG (2012), in line with the objective of this study. The second filter was importing these studies into a tool that would help eliminate duplicate papers retrieved from different databases. The third filter was used to look up titles, abstracts and keywords. The criterion for inclusion was a link between KM, PM and sustainability.

Step 4: relevant information were systematised and organised. Next, an analysis and compilation of texts of interest was conducted, based on the criterion described. It was decided not to focus on specific countries or regions, in the interest of sample size. The texts that were finally selected, which presented the expected link between the themes, resulted in approximately 84 studies in between 2004 and 2012, as well as the bibliographies already established on the topics surveyed.

\section{Knowledge management}

Sun and Hao (2006) define KM as the creation of management processes and infrastructure to bring knowledge and communications together in a common ecology that should support the creation, utilisation and retention of knowledge. Various authors (Drucker 1993; Davenport, et al. 1996; Burstein \& Holsapple 2008) confirm that the good initiatives and practices of KM contribute to the sustainability of the competitive advantages of organisations.

Knowledge can be classified into two basic types - tacit and explicit - which Nonaka and Takeuchi (1995: 7) defines as:

Tacit: is highly personal and hard to formalize, making it difficult to transmission and sharing with others. Conclusions, insights and subjective hunches fall into this category of knowledge. Furthermore, tacit knowledge is deeply rooted in the actions and experiences of an individual as well as their emotions, values or ideals.

Explicit: can be expressed in words, numbers or sounds, and shared in the form of data, scientific formulas, visual aids, audio tapes, product specifications or manuals. Thus, knowledge is seen as a synonym of a computer code, a chemical formula or a set of general rules.

One way to facilitate the exchange of knowledge, thus enabling the exchange of experience which then allows for the building of synergy between projects and permits a greater level of organisational knowledge, is what Nonaka and Takeuchi (1995) refer to as the "theory of the creation of organizational knowledge", which is nothing more than the evolutionary integration between tacit and explicit knowledge, by way of cycles, which became known in the literature as the SECI process, which can be better visualised in figure 1. 


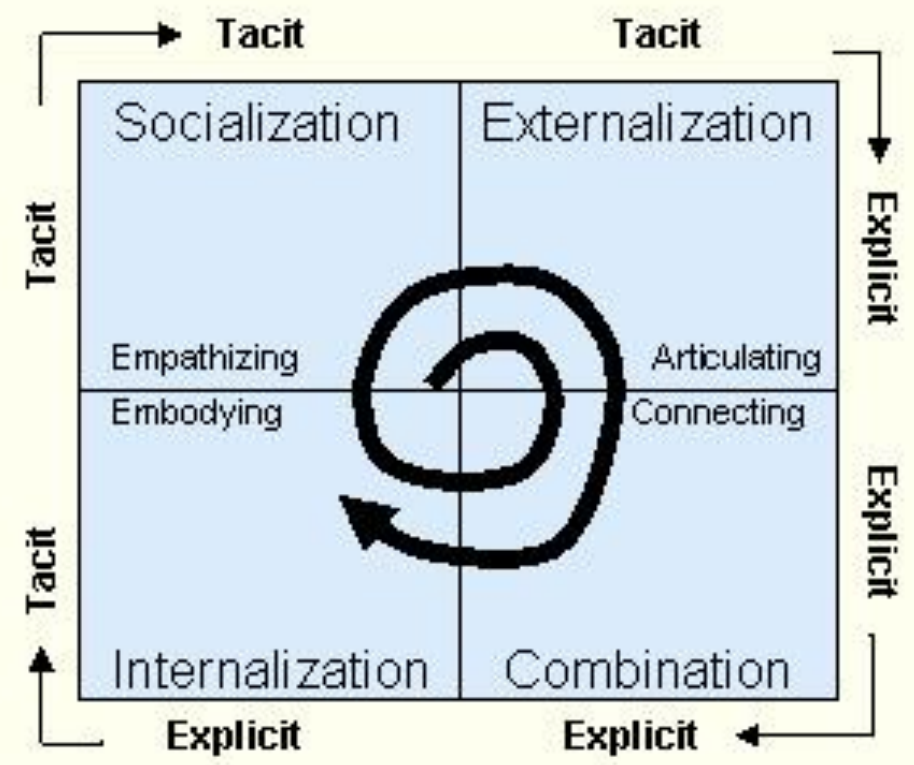

Figure 1. SECI model

Source: Nonaka and Takeuchi (1995)

By using the SECI process one can better address the four conversion modes, according to Takeuchi and Nonaka (2004: 23)

\begin{abstract}
Socialization: To share and create tacit knowledge through direct experience.
Externalization: To articulate tacit knowledge through dialogue and reflection.

Combination: To systematize and apply explicit knowledge and information.

Internalization: To learn and acquire new tacit knowledge in practice.
\end{abstract}

$\mathrm{KM}$ consists, essentially, of easing the processes of creation, sharing, and utilisation of knowledge. It is not about implanting a new department, or a new computerised management system, but about introducing changes within the work methods. There are many ways to approach KM, and each organisation can define its own. This organisational knowledge evolution, using the methods, techniques and tools provided by KM, could gradually provide opportunities for portfolio integration and, consequently, corporate sustainability.

\title{
Project integration by way of knowledge management
}

Project integration is not a usual concern in the current reality. As a result, it suffers a series of obstacles, which end up turning something that was supposed to be trivial into something big and complex. One of the fundamental points to making project integration more feasible is the use of KM, which is able to provide and maintain a knowledge-based system, appropriate, integral and integrated into the various scenarios of the portfolio.

Figure 2 shows a study of benchmarking carried out in some countries by the Project Management Institute (PMI), the PMSURVEY.ORG (2012). It shows that a majority of companies do not use or do not give enough weight to the use of KM focused on projects through specific tools. 


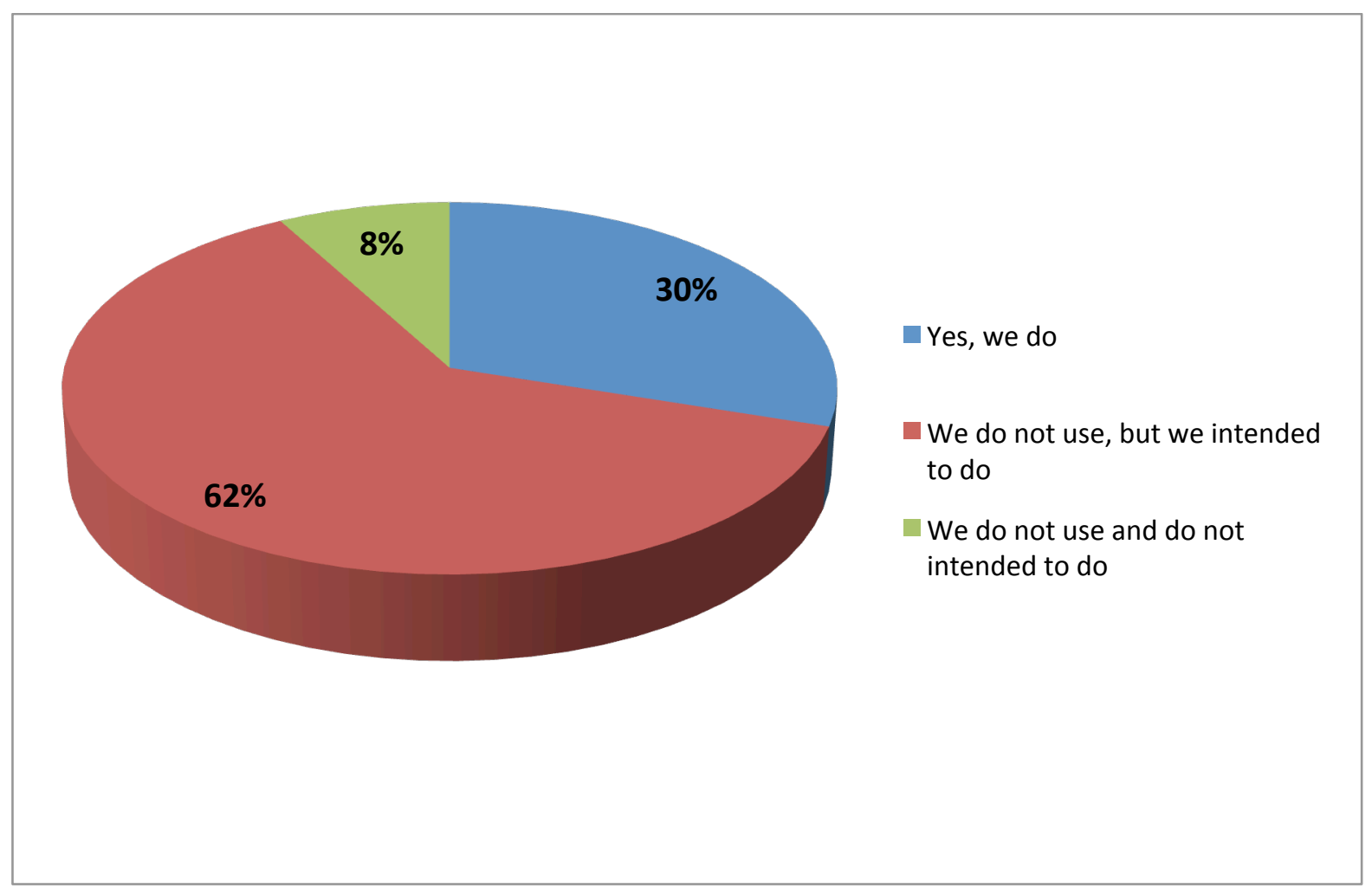

Figure 2. Use of tool for the management (storage and recuperation) of knowledge acquired in projects

Source: PMSURVEY.ORG (2012)

To make the "journey" of this interconnection search possible, KM efficiently provides the methods and techniques of creation, sharing and utilisation of knowledge, which can be valid for use in different cases, each with its own characteristics and usability, and which make knowledge and the ability to create and utilise it the most important sources of competitive advantage, capable of sustaining a company (Drucker 1993; Grant 1996; Nonaka 1990, 2007, 1994; Nonaka \& Takeuchi 1995).

KM provides several ways to effectively take advantage of knowledge creation: creativity and innovation, value analysis, PM, patent analysis, market research, knowledge acquisition, exit interviews, heuristic redefinition, classic brainstorming, brainwriting 6-3-5, imaginary brainstorming, TILMAG, morphological matrix, etc. While the creation of knowledge is important, the sharing of knowledge for project integration and corporate sustainability, as well as the gradual implementation of a knowledge organisation, is equally important. Therefore, the use of the following "artifacts" takes on the utmost importance: benchmarking, continuous improvement (PDCA), communities of practice, knowledge cafe, best practices, team-building, social network analysis, storytelling, return of experiences, and peer assistance, among others. The utilisation of knowledge offers its respective "tools" for discovering the risks, exposures and key opportunities: technological foresight (foresight), scenario building, backcasting and risk management (Rao 2004; APO 2010).

Apart from all the methods mentioned above, which can make this integration feasible, organisations' interest in structuring their data in such a way as to allow them to make safe decisions has enabled them to utilise a very important information system for one of the main artifacts for the natural integration of their portfolio, namely, organisational memory. Organisational memory is "stored information from the history of an organization that can be 
used in making present day decisions" through a process of social articulation, exchange and sharing of information, leading to a shared model or interpretation of the world. Thus, organisational memory is the means by which organisational knowledge is transferred from the past to the present, and therefore enables the organisational learning of projects and programs, for the Project Management Office, which can articulate this information in a more appropriate and effective way. This is commonly known as "lessons learned" (PMBOK 2008).

Schindler and Eppler (2003) addressed the acquisition and sharing of knowledge in projects on a case study done in some companies and elucidate the importance of implementing a process of lessons learned, based on specific goals with the use of signs. They emphasise this importance in Figure 3, which shows the development project of a truck, divided into phases, which at one stage has the objective to acquire/learn and thus subsequently be able to share this knowledge for the integration of other projects (Schindler \& Eppler 2003). Other authors also consider the importance of acquiring and sharing knowledge for better learning and subsequent integration of that knowledge into other teams and projects (Fong 2003; Huang \& Newell 2003; Kasvi, et al. 2003).

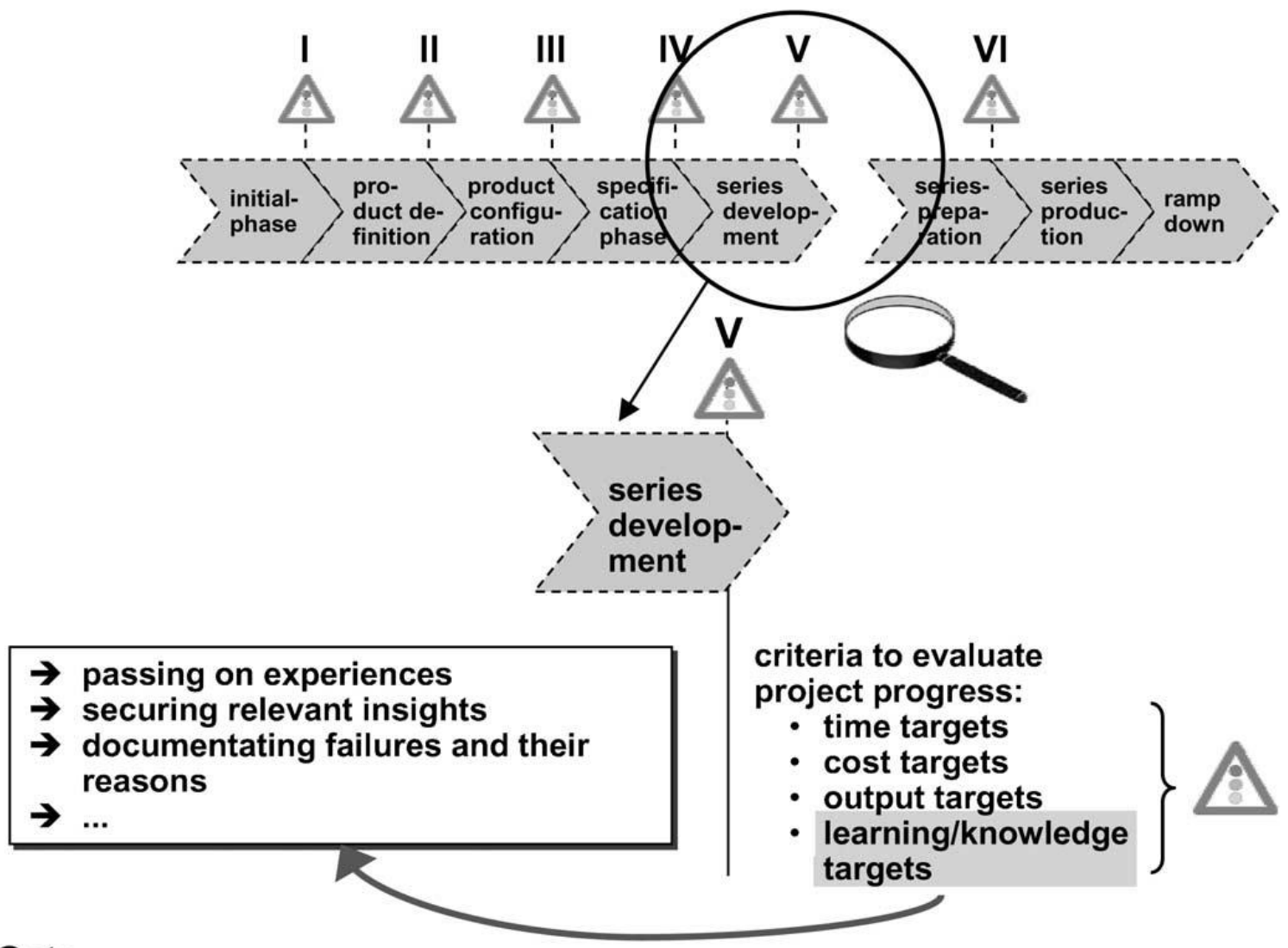

Gate

Figure 3. Modified gate concept (example)

Source: Schindler \& Eppler (2003)

Kasvi, et al. (2003) explain that the difficulty of projects in organisations is that they are part of a larger outcome, and are commonly used for maintain competitive advantage. Hence, this knowledge is not shared. The authors' work is based on the study of three cases, which deal with the knowledge involved in projects of different types of organisations (universities, small and medium-sized enterprises, research institutions and international companies, among others). An important point of their study was to discover the sources of knowledge 
acquisition for these diverse companies, as seen in Figure 4, as well as the type of knowledge involved (Figure 5).

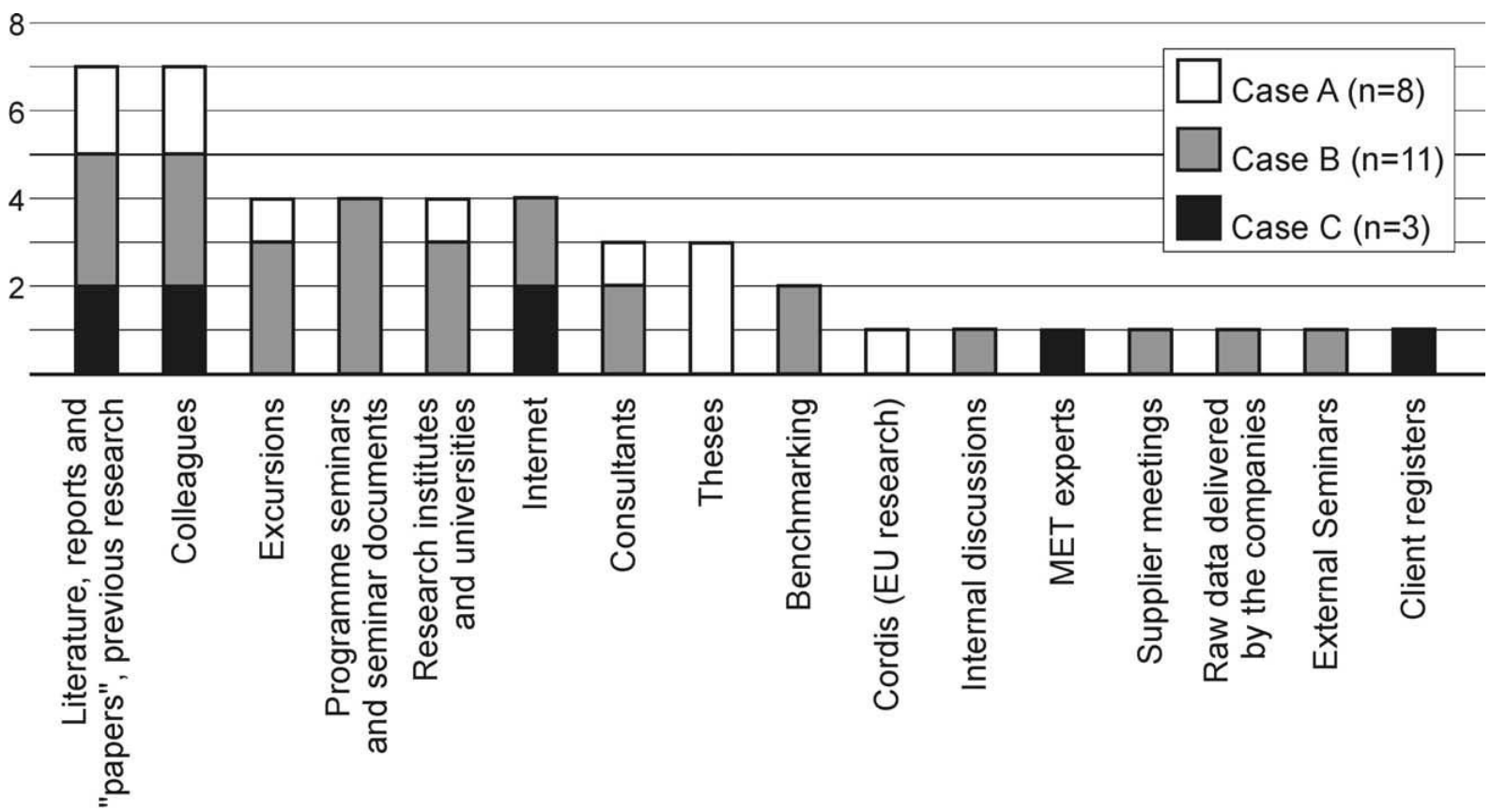

Figure 4. Frequencies of the knowledge sources used in the case projects as mentioned by the interviewees

Source: Kasvi, et al. (2003)

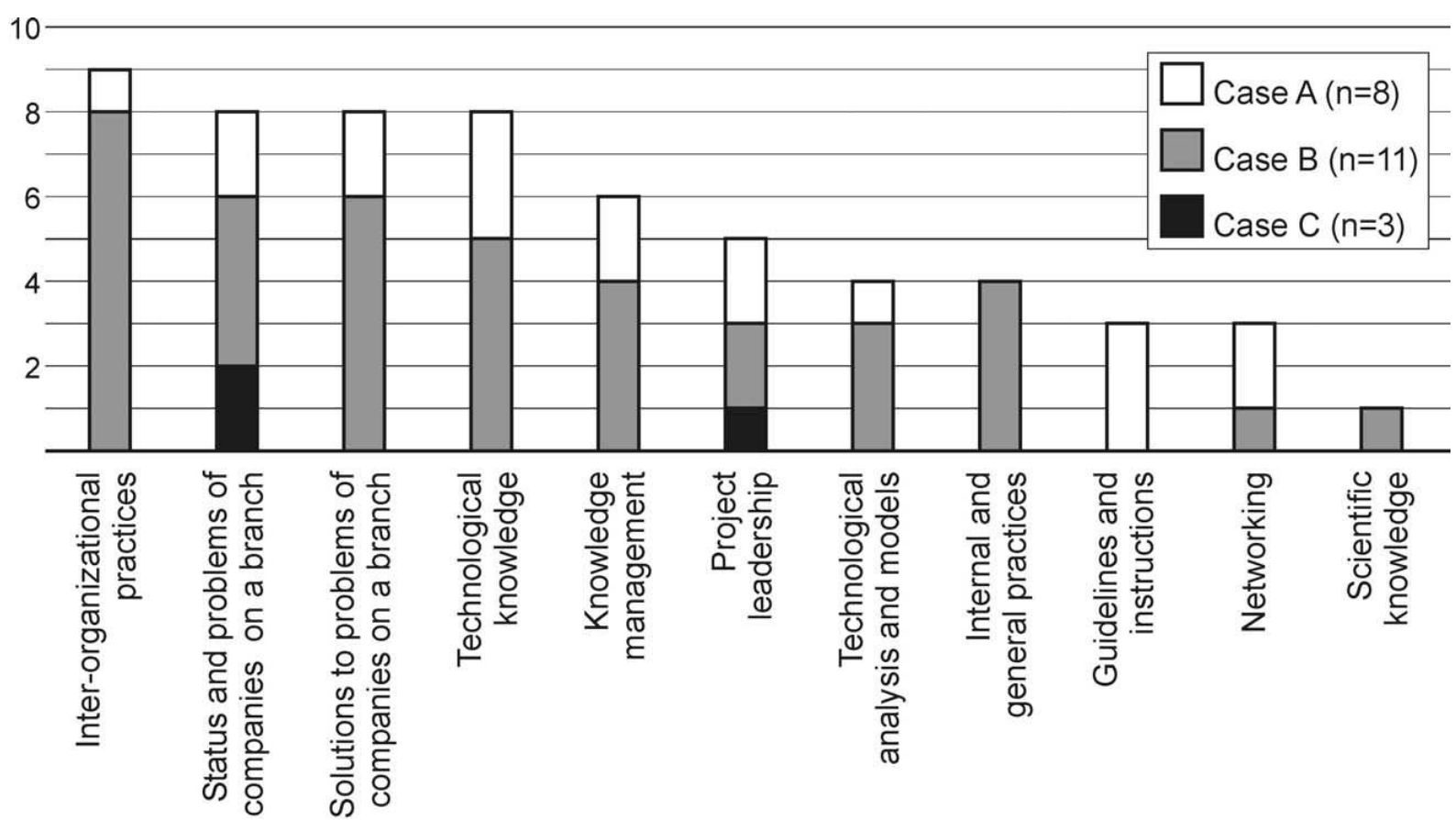

Figure 5. Frequencies of the various kinds of new knowledge produced in the case projects as mentioned by the interviewees

Source: Kasvi, et al. (2003)

With the correct and effective use of these methods and techniques, adapting each to the desired scenarios, continuously adapting to the necessary changes, the portfolio integration 
winds up being more natural, allowing for a sustainability that is more constant and adheres to the versatile aspects of this study, thus providing a weighted balance of corporate worth (Fong 2003; Huang \& Newell 2003; Kasvi, et al. 2003).

\section{Corporate sustainability and its association with value}

For any company to acquire corporate sustainability, the financial capital, human capital and natural capital should be integrated and balanced. The scarcity of natural resources and social dissonances increasingly common in our society are generating operational restrictions, but can also denote opportunities for progress and the capturing of new markets, with a weighting of company resources toward long-term business results with prerogatives that enhance the quality of life for present and future populations (Dixon \& Fallon 1989; Daly, et al. 1999; Wheelen \& Hunger 2011).

There is no single definition for corporate sustainability, but there is general agreement that sustainable business development must be expressed in an environment that determines the quality and availability of human and natural capital associated with financial and industrial capital. As a result of this new business practice, the concept of Tripple Bottom Line (TBL) has emerged. This indicates the interaction between the financial, environmental and social results in the measurement of corporate sustainability, and is an important step in the quest for management excellence. It demonstrates that economically viable, environmentally responsible and socially just businesses are the key differentiators in the market, as explained below (Elkington, 1994, 1997).

As in the previous concept, an organisation was "sustainable" if from the economic point of view it was stable, i.e it had a considerable asset and profit growth in full, even with debt. For some countries, the concept included a social bias on some aspects (Elkington 1997; Porter 1998; Wheelen \& Hunger 2011). The ecological part of the TBL brought therefore, verification and a problem. If the entrepreneurs and governments do not worry about the environmental aspect they could end up complicating the matter, without inputs and, perhaps, without the consumer, besides contributing to the destruction of the planet.

To address this new concept, companies should tailor their strategies to the three main points (3P) cited by Elkington (1997):

People, or human capital. This refers to fair, ethical, and beneficial business practices toward employees, community, and country in which a corporation conducts its business.

Planet, or natural capital. The goal of $21 \mathrm{st}$-century companies is to not only help protect the environment by producing Green or environmentally responsible products but also to have their own sustainable, environmentally sound business operating practices. This means companies are to operate in an environmentally responsible manner, taking steps to reduce their own environmental footprint, consuming less energy and fewer nonrenewable resources and producing less waste.

Profit. Yes, companies are still in the business of making profits; however, within a sustainability framework, profit is viewed as the economic benefit enjoyed not just by the company but by the employees and community as a whole.

In order to demonstrate that sustainability has become a concern in the globalised world, and that organisations, government and civil societies are engaged in the search for practices that seek to cover the 3P through more elaborate projects, the presentation of the Sustainable Development Indicators becomes important. It shows how necessary the investment in 
research and development (R\&D), among other things, is to making KM for sustainability feasible, as seen in Figure 6, found in the UIS Fact Sheet (2011).

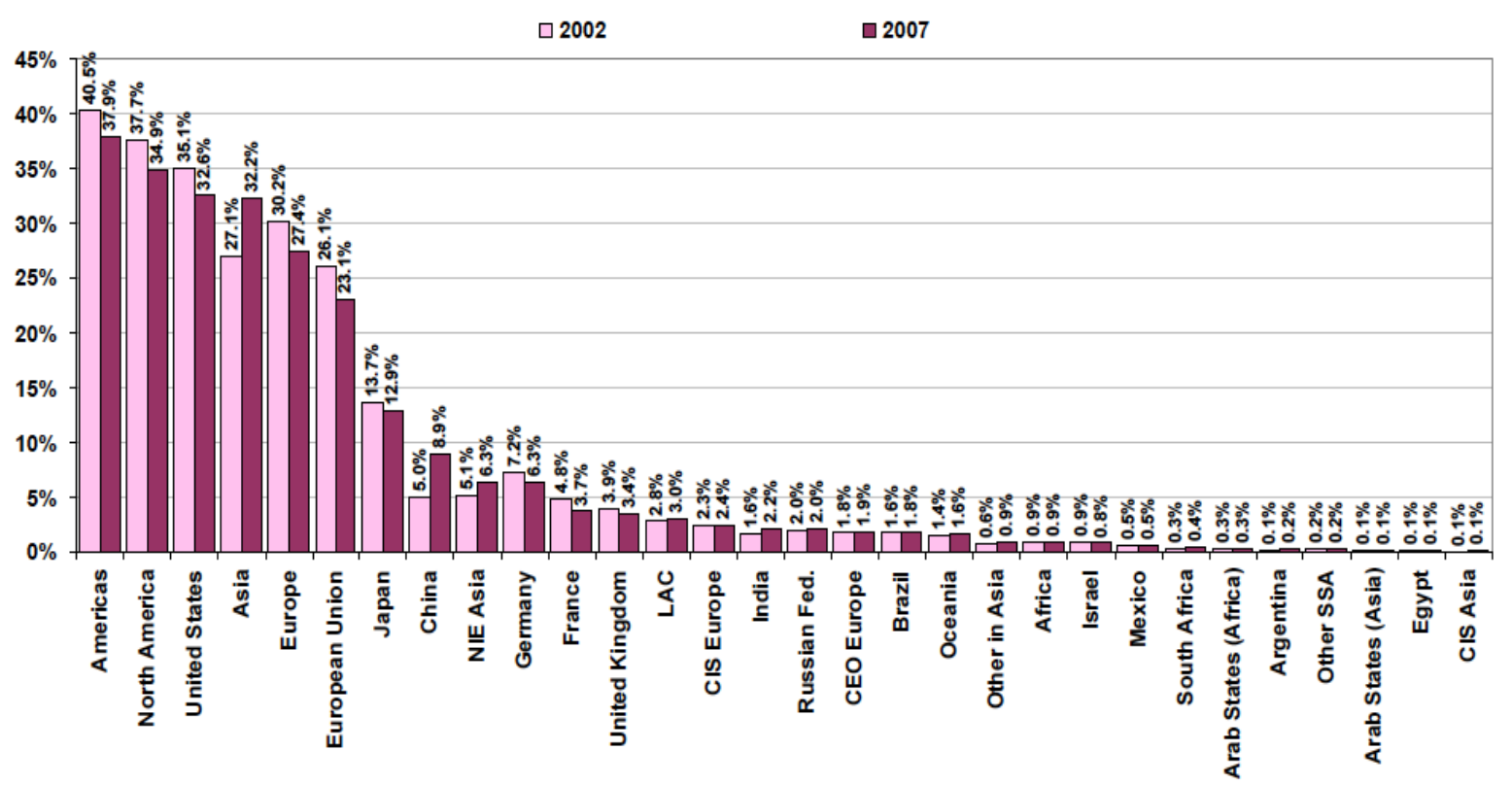

Figure 6. Distribution of R\&D expenditure in the world

Source: UIS Fact Sheet (2011)

The profitability of individual firms increasingly links the ability to anticipate and meet emerging trends and behaviours that transform and influence people, in an ever more rapid and forceful way, and if the strategic planning does not consider these changes in its policies, business success will be affected. The passive worker and environment are becoming quality indicators of companies and also regulators of public empathy and market share. Projects must be grounded in a rigorous process of using KM to address effectively the complex relationships between the company, the natural environment and the social environment, to meet their intrinsic demands (Porter 1998).

Once decoded this way, the practice and continued spread of KM could be a leading market factor and also a reference in standard industry and regulatory frameworks, reaching intangibles difficult to measure, since associated with the idea of corporate sustainability comes the concept of externalities, distributed by the branch of classical microeconomics known as welfare economics (Feldman 1980); external unintended effects, positive or negative, of entrepreneurial activity on economic agents. Due to the complexity of measuring the costs of externalities, integrated PM via KM, should take a firm stance to counteract and measure socio-environmental impacts that may affect the operating results and, in this sense, provide an effective control of the natural mechanisms involved in contrast to the business standards adopted to avoid generating additional operating costs or loss of income, depending on the interrelationships of the environment and company (Porter 1998; Wheelen \& Hunger 2011).

The alleged conflict between economic, social and environmental objectives is a fallacy, because no company maintains itself and much less progresses without positive financial results, and it doesn't make sense to confront them with the social and environmental results. Every day PM should integrate these in a balanced manner, following the recommendation of the game theory, which suggests a need for equalisation between cooperation and 
competition, as the perfect strategic interaction, appropriate to each context, naturally linking portfolio integration to corporate sustainability through KM (Kerzner 2010; Wheelen \& Hunger 2011).

\section{Summary and recommendations}

As demonstrated in this study, the use of KM as a means of supporting the integration of projects and corporate sustainability unfortunately ends up being restricted to a few effective cases. Some of the methods, techniques and information systems discussed above could be used for PM. The PMO could envision possible scenarios, opportunities and legitimate consolidation of much information and past experiences, encouraging the creation and dissemination of knowledge of those involved, innovation, intellectual capital formation and thus, gradually, knowledge organisations, with a high level of competence. This would bring many benefits that a knowledge-based system can provide such as minimising future surprises, mitigation of project risks and increasing the return on investment.

The effective use of KM to join forces with the PM is capable of producing artifacts extremely relevant to strategic management of organisations, thus achieving significant results in the matters referred to above, as well as in continuous improvement. However, the gap between these areas can generate numerous studies that could be widely used for many economically viable businesses, and in the utilisation of knowledge-based systems for better integration and usability between KM and PM.

Many methods, techniques and tools of KM are available to PM due to its use throughout the life cycle of projects, so it may be interesting to the study of frameworks applied in the knowledge involved in PM and how these can be best used in future projects. Finally, another future contribution could be the use of KM frameworks in empirical studies related to PM.

\section{References}

Asian Productivity Organization (APO) 2010, Online, Available at: http://www.apotokyo.org/publications/files/ind-43-km tt-2010.pdf (Accessed 6 December 2012).

Burstein, F. \& Holsapple, C.W. 2008, Handbook on Decision Support Systems 2, Springer Verlag, New York.

Cooper, H.M. 1998, Synthesizing Research: A Guide for Literature Review, 3nd ed., Sage Publications, California.

Davenport, T.H., Jarvenpaa S. \& Beers M. 1996, Improving knowledge work processes, Chemtech, vol. 26 , no. 10, 14-23.

Daly, H.E., Prugh, T. \& Constanza, R. 1999, The Local Politics of Global Sustainability, Island Press, Washington.

Dixon, J.A., Fallon, L.A. 1989, The concept of sustainability: origins, extensions, and usefulness for policy, Society \& Natural Resources, vol. 2, no 2, 73-84.

Drucker, P.F. 1993, Post-Capitalist Society, Harper Paperbacks, New York.

Drucker, P.F. 1998, Intellectual Capital: The New Wealth of Organizations, Crown Business, New York.

Drucker, P.F. 2003, Managing in the Next Society. St. Martin's Griffin, New York.

Drucker, P.F. 2010, The Drucker Lectures: Essential Lessons on Management, Society and Economy, McGrawHill, New York.

Elkington, J. 1994, Towards the sustainable corporation: win-win-win business strategies for sustainable development, California Management Review, vol. 36, no 2, 90-100.

Elkington, J. 1997, Cannibals with Forks: the Triple Bottom Line of 21st Century Business, Capstone, London,. Feldman, A.M. 1980, Welfare Economics and Social Choice Theory. Martinus Nijoff, Boston.

Fong, P.S.W. 2003, Knowledge creation in multidisciplinary project teams: an empirical study of the processes and their dynamic interrelationships, International Journal of Project Management, vol. 21, no. 7, 479486.

Grant, R.M. 1996, Toward a knowledge-based theory of the firm, Strategic Management Journal, vol. 17, no. 7, 109-122.

Kasvi, J.J.J., Vartiainen, M. \& Hailikari, M. 2003, Managing knowledge and knowledge competences in projects and project organisations, International Journal of Project Management, vol. 21, no. 8, 571-582 
Kerzner, H. 2010, Project Management - Best Practices: Achieving Global Excellence. 2nd ed., Wiley, New York.

Leedy, P.D. \& Ormrod, J.E. 2001, Practical Research: Planning and Design. 7th ed., Merrill Prentice Hall, New Jersey.

Levy, Y. \& Ellis, T.J. 2006, A systems approach to conduct an effective literature review in support of information systems research, Informing Science Journal, vol. 9, 181-212.

Nonaka, I. 1990, Management for Knowledge Creation. Nihon Keizai Shimbun-sha, Tokyo.

Nonaka, I. 1994, A dynamic theory of organizational knowledge creation, Organization Science, vol. 5, no 1, 1437.

Nonaka, I. \& Takeuchi, H. 1995, The Knowledge-Creating Company: How Japanese Companies Create the Dynamics of Innovation. Oxford University Press, New York.

Nonaka, I. 2007, The knowledge-creating company, Harvard Business Review, vol. 85, no 7-8, 162-171, 194.

Peppard, J. 2007, The conundrum of IT management, European Journal of Information Systems, vol. 4, no 16, 336-345.

Project Management Institute 2012, PMSURVEY.ORG 2012 Edition. Project Management Institute Chapters. Online, Available at: www.pmsurvey.org (Accessed 23 February 2012).

Porter, M. E. 1998, Competitive Advantage: Creating and Sustaining Superior Performance. Free Press, New York.

Project Management Institute 2008, A Guide to the Project Management Body of Knowledge. 4th ed., PMI, Pennsylvania.

Rao, M. 2004, Knowledge Management Tools and Techniques: Practitioners and Experts Evaluate KM Solutions. Butterworth-Heinemann, Burlington,

Reich, B.H., Gemino, A., Sauer, C. 2008, Modeling the knowledge perspective in IT projects, Project Management Journal, vol. 39, S4-S14 (Supplement).

Schindler, M. \& Eppler, M.J. 2003, Harvesting project knowledge: a review of project learning methods and success factors, International Journal of Project Management, vol. 21, no. 3, 219-228.

Sun, Z. \& Hao, G. 2006, HSM: A hierarchical spiral model for knowledge management, Proceedings of the 2nd International Conference on Iinformation Management and Business, Faculty of Commerce Papers, Faculty of Commerce, University of Wollongong, 542-555.

Takeuchi, H. \& Nonaka, I. 2004, Hitotsubashi on Knowledge Management, Wiley, New York.

UIS Fact Sheet 2011. Online, Available at: http://www.uis.unesco.org/FactSheets/Documents/fs15 2011investments-en.pdf (Accessed 19 October 2012).

Webster, J. \& Watson, R.T. 2002, Analyzing the past to prepare for the future: writing a literature review, Management Information Systems Quarterly, vol. 26, no. 2, 13-23.

Wheelen, T.L. \& Hunger, J.D. 2011, Strategic Management and Business Policy: Toward Global Sustainability. 13th ed., Prentice Hall, New Jersey.

\begin{abstract}
About the authors
Everton Michels graduated in Computer Science from the University of Southern Santa Catarina (Unisul). He has a specialisation degree in Project Management from the SATC Faculty, and took special disciplines at the Graduate Program in Engineering and Knowledge Management at the Federal University of Santa Catarina (UFSC). He is currently is a student of special disciplines at the Graduate Program of Production Engineering (UFSC). He is a certified PMP, CSM, Coach and MCTS, volunteer in PMI-SC and communities Organisational Project Management and PMI Agile. He has expertise in Progress, Itil, Cobit, UML, best practices of PMI, Agile methods, among others. He has over 10 years of IT experience and is currently an IT project manager in the private social security sector.
\end{abstract}

Paulo Eduardo Antunes Grijó graduated in Administration from Santa Ursula University. He completed postgraduate studies in Marketing at Superior School of Propaganda and Marketing (Rio de Janeiro). He has a Master of Environmental Engineering degree from Santa Catarina Federal University and considerable experience in the field, with emphasis on environmental management, working mainly in the following areas: recovery of dangerous wastes, environmental management, sustainability, environmental education and ecoefficiency. He is the founder of the Marbras Et Mundi Project, which has developed technologies to recover wastes generated in the manufacturing of surfboards, and is a referential model of environmental management for this sector. He is a doctoral candidate at the Postgraduate Program in Knowledge Management Engineering at Santa Catarina Federal University.

Elizandra Machado is a doctoral candidate in the Production Engineering Postgraduate Program at the Federal University of Santa Catarina (PPGEP/UFSC). She has a Masters degree in Engineering and Knowledge Management (EGC/UFSC) with emphasis in Knowledge Management. She is a specialist in Strategic Marketing 
Management and Business at UFSC and is a graduate in Business Administration with specialisation in Information Management (Faculty of Pato Branco - FADEP). She has experience in retail and hospital management. Currently, she is a professor and consultant in the areas of marketing and sales.

Paulo Mauricio Selig graduated in Mechanical Engineering from the Federal University of Rio Grande Do Sul (UFRGS), and has a Masters degree in Production Engineering from the Federal University of Santa Catarina (UFSC), and a PhD in Production Engineering (UFSC) and completed postdoctoral research (UFRGS). He is currently a professor at the Universidade Federal de Santa Catarina, a member of the Association of Engineering and Value Analysis and a member of the Brazilian Association of Production Engineering. He has experience in production engineering, with emphasis on knowledge management, working on the following topics: performance indicators, balanced scorecard, cost, value analysis, process management and environmental management. Currently, he is the Coordinator of the Postgraduate Program of Engineering. 